\title{
THE EFFECT OF HOLE BURNING ON SELECTIVELY EXCITED SPECTRA
}

\author{
(Presented by K. K. Rebane)
}

\begin{abstract}
An impurity system in a solid matrix is considered, where photoinduced transitions can occur between several spectrally non-equivalent quasi-stable configurations of the impurity. At the equilibrium between configurations, reached under a monochromatic excitation, the luminescence spectrum does not depend on the excitation frequency. If the equilibrium is reached via the absorption in the Lorentzian absorption lines of individual configurations, the resulting steady-state excitation spectrum contains a single Lorentzian line of a width determined by the dispersion of the frequencies of the optical transition for different configurations. In the presence of an additional static inhomogeneous broadening the transitions between different configurations cause a broadening of the holes in the spectrum and an anomalous low-temperature behaviour of luminescence line intensities in the selectively excited spectrum observed earlier for impurities in glassy matrices.
\end{abstract}

The selective (laser) excitation of luminescence $\left[{ }^{1,2}\right]$ is widely used in the spectroscopy of impurities in low-temperature solid matrices. It enables one to eliminate a considerable part of the inhomogeneous broadening of spectra and to come closer to the hidden homogeneous structure. The peculiarities of this method are well understood for the systems with the static distribution of transition energies $\left[{ }^{3}\right]$. In many cases, however, this distribution cannot be considered as an absolutely static one. Particularly, it may be altered by a photoinduced transformation of impurity centres. On the basis of this phenomenon the hole burning method was developed $\left[{ }^{4,5}\right]$ to determine homogeneous linewidths. The aim of this paper is to consider how such photoinduced transformation affects selectively excited spectra.

\section{Model}

We suppose that $N$ quasi-stable configurations of an impurity centre exist. These may be configurations differing by the disposition of some internal groups in molecular impurities, by the orientation of the guest molecule in the host matrix, by the arrangement of adjacent host molecules, etc. Each such configuration is characterized by the integral absorption cross-section $\sigma_{i}$ and the normalized absorption spectrum $\varkappa_{i}(v)$, which in general differ for different configurations $(i=1, \ldots, N)$. Between configurations after an optical excitation the transitions can occur, which are characterized by the yields $\eta_{i j}$ (the probability to trans- 
fer from the configuration $i$ to the configuration $j$ per absorbed photon). It is supposed that

$$
\sum_{\substack{j=1 \\(i \neq j)}}^{N} \eta_{i j} \ll 1,
$$

as a result of which these transitions do not seriously affect the spectra of individual configurations. We also suppose that from any configuration every other configuration is obtainable, possibly via some intermediate steps. We neglect the transitions between configurations in the ground electronic state. As demonstrated by hole burning experiments, this is a justified approximation for many low-temperature systems, where the holes remain stable in the darkness for the times well exceeding the burning time $\left[{ }^{4,5}\right]$.

To consider an ensemble of such impurities in a real matrix, one has to allow for static inhomogeneity, i. e. static variations of local conditions in the matrix. This makes the parameters $\sigma_{i}, x_{i}$, and $\eta_{i j}$ for every given $i, j$ vary from impurity to impurity. We postpone, however, the discussion of related effects and consider here an ideal system of identical impurities $\left(\sigma_{i}, x_{i}\right.$, and $\eta_{i j}$ for every given $i, j$ coinciding for all impurities, respectively). Of course, actual configurations of different impurities at a given time may be different and in general they are time-dependent. If such an ensemble is exposed to a monochromatic light of a spatially uniform photon flux $I_{0}$ and frequency $v_{e}$, the kinetics are given by

$$
\dot{n}_{i}=-\left[I_{0} \sigma_{i} \varkappa_{i}\left(v_{e}\right) \sum_{j=1}^{N} \eta_{i j}\right] n_{i}+\sum_{j=1}^{N} I_{0} \sigma_{j} \varkappa_{j}\left(v_{e}\right) \eta_{j i} n_{j}, \quad i=1, \ldots, N,
$$

$n_{i}$ being the relative population of the $i$-th configuration. The phototransformation is supposed to proceed via one-step excitation, resulting in the linear dependence of the reaction rate on the photon flux $I_{0}$. The latter is supposed to be sufficiently small to avoid optical saturation [ $\left.{ }^{6}\right]$.

In what follows, we consider the dynamical equilibrium between different configurations, reached after sufficiently long excitation (values of excitation times needed for real systems are discussed below). The stationary populations $n_{i}^{\infty}$ are obtained from

$$
-\sigma_{i} \varkappa_{i}\left(v_{e}\right)\left(\sum_{j=1}^{N} \eta_{i j}\right) n_{i}^{\infty}+\sum_{j=1}^{N} \sigma_{j} \varkappa_{j}\left(v_{e}\right) \eta_{j i} n_{j}^{\infty}=0, \quad i=1, \ldots, N .
$$

As may be easily verified,

$$
n_{i}^{\infty}=C\left(v_{e}\right) \bar{n}_{i} / \varkappa_{i}\left(v_{e}\right)
$$

where

$$
C\left(v_{e}\right)=\left[\sum_{j=1}^{N} \bar{n}_{j} / \varkappa_{j}\left(v_{e}\right)\right]^{-1}
$$

is a coefficient, providing normalization $\sum_{j=1}^{N} n_{j}^{\infty}=1 . \bar{n}_{i}$ are obtained from

$$
-\sigma_{i}\left(\sum_{j=1}^{N} \eta_{i j}\right) \bar{n}_{i}+\sum_{j=1}^{N} \sigma_{i} \eta_{j i} \bar{n}_{j}=0, \quad i=1, \ldots, N,
$$

and do not depend on the excitation frequency. The normalization 


$$
\sum_{j=1}^{N} \bar{n}_{j}=1
$$

is also supposed. Physically $\bar{n}_{i}$ are equilibrium populations under a broad-band (white) excitation. Since (2) does not depend on $I_{0}$, the stationary populations $n_{i}^{\infty}$ are also intensity-independent. $I_{0}$ determines only the times at which dynamical equilibrium is reached.

As is seen from (3), the populations of efficiently excited configurations (large $x_{i}\left(v_{e}\right)$ ) are reduced compared to their values under broad-band excitation: impurities are «burned out» from these configurations and stored in the weakly excited ones. This has essential consequences on selectively excited spectra, as will be demonstrated below.

\section{Stationary spectra}

If the monochromatic excitation is spatially uniform and reabsorption is absent, the luminescence intensity at the frequency $v_{f}$ for our model is given by

$$
I_{f}\left(v_{f}\right)=I_{0} \sum_{i=1}^{N} \sigma_{i} \varkappa_{i}\left(v_{e}\right) \eta_{i} \varphi_{i}\left(v_{f}\right) n_{i},
$$

i. e. the total luminescence spectrum is a sum of the luminescence spectra of excited impurities. $\eta_{i}$ and $\varphi_{i}$ in (6) are the luminescence quantum yield and normalized luminescence spectrum for the $i$-th configuration, respectively. For the stationary case, using (3), (4), one obtains

$$
I_{f}^{\infty}\left(v_{f}\right)=I_{0} C\left(v_{e}\right) \sum_{i=1}^{N} \sigma_{i} \eta_{i} \varphi_{i}\left(v_{f}\right) \bar{n}_{i} .
$$

It follows from (7) that the shape of the selectively excited luminescence spectrum in this case does not depend on the excitation frequency and coincides with that under broad-band excitation. It should be mentioned that a similar effect occurs in the systems with inhomogeneously broadened spectra where an effective energy transfer takes place, providing equilibrium between impurities before emission [ $\left.{ }^{7}\right]$. In our case the physical reasons are, however, rather different and consist in a specific compensational mechanism: the reduction of the relative number of most effectively absorbing impurities is compensated by a more effective excitation of their luminescence.

As follows from (7), the stationary excitation spectrum, i.e. the dependence of integral luminescence intensity on the excitation frequency is given by

$$
I_{e}^{\infty}\left(v_{e}\right)=I_{0}\left(\sum_{i=1}^{N} \sigma_{i} \eta_{i} \bar{n}_{i}\right) C\left(v_{e}\right),
$$

i. e. it is proportional to $C\left(v_{e}\right)$.

Typical low-temperature absorption and luminescence spectra of an impurity centre (homogeneous spectra) consist of narrow no-phonon lines $(\mathrm{NPL})$ and broad phonon wings (PW) $\left[{ }^{8}\right]$. For the narrowest NPL purely electronic line (PEL) - the limiting width at $T \rightarrow 0$ is determined by the lifetime of the excited state and is of the order of $10^{-3} \mathrm{~cm}^{-1}$ for a dipole transition. The width of the PEL is essentially temperaturedependent, increasing by an order of magnitude or more from zero to 
the liquid He temperature $\left[{ }^{9}\right]$. The relative intensity of NPL compared to the total intensity of NPL and its PW - the Debye-Waller factor (DWF) $\alpha-$ is determined by the Stokes losses and is also dependent on temperature (decreases with it). For the systems of intermediate electron-phonon interaction the integral intensities of NPL and its PW are comparable at liquid He temperature. A typical width of $\mathrm{PW}$ is of $100 \mathrm{~cm}^{-1}$. The large difference of NPL and PW widths results in a large ratio of NPL and PW peak intensities $\left(10^{3}-10^{5}\right)$.

We adopt the Lorentzian form for NPL considered and suppose its full width at half maximum (FWHM) to be the same (2T) for all configurations which differ by the frequencies of NPL maxima $\omega_{i}$ :

$$
\varkappa_{i}(v)=\pi^{-1} \Gamma /\left[\Gamma^{2}+\left(v-\omega_{i}\right)^{2}\right], \quad i=1, \ldots, N .
$$

Further we suppose the equilibrium between different configurations to be provided by the absorption in NPL only. This is a justified approximation if

$$
\max _{i}\left|v_{e}-\omega_{i}\right| \leqslant \sqrt{\Gamma \Gamma_{p} \alpha /(1-\alpha)}
$$

with $\Gamma_{p}$ being the PW width. (10) is obtained comparing the absorption in NPL with the mean value of that in PW $\sigma(1-\alpha) / \Gamma_{p}$. For the systems with intermediate electron-phonon interaction at low temperatures $\sqrt{\Gamma \Gamma_{p} \alpha /(1-\alpha)} \approx 1-10 \mathrm{~cm}^{-1}$. At an excitation in spectral region (10), the absorption in NPL prevails over that in PW. To satisfy (10),

$$
\max _{i, j}\left|\omega_{i}-\omega_{j}\right| \leqslant \sqrt{\Gamma \Gamma_{p} \alpha /(1-\alpha)}
$$

must hold, which limits the dispersion of the frequencies $\omega_{i}$.

From (4), (8), (9) one obtains now

$$
I_{e}^{\infty}\left(v_{e}\right) \sim C\left(v_{e}\right)=\pi^{-1} \Gamma /\left[\Gamma^{2}+\Delta^{2}+\left(v_{e}-\bar{\omega}\right)^{2}\right],
$$

where

$$
\begin{aligned}
\bar{\omega} & =\sum_{j=1}^{N} \omega_{j} \bar{n}_{j}, \\
\Delta^{2} & =\sum_{j=1}^{N}\left(\omega_{j}-\bar{\omega}\right)^{2} \bar{n}_{j} .
\end{aligned}
$$

Excitation spectrum (12) consists of a single Lorentzian line with the peak frequency $\bar{\omega}$ and FWHM $2 \sqrt{\Gamma^{2}+\Delta^{2}}$ determined by the first and second central moments (13) of the distribution

$$
\bar{\varrho}(\omega)=\sum_{i=1}^{N} \bar{n}_{i} \delta(\omega-\omega i) .
$$

The conclusion about the Lorentzian shape of the excitation spectrum holds even if some variations of $\Gamma$ occur for different configurations. This modifies but slightly the calculation of the linewidth and peak position.

For $\Delta>\Gamma$ the width of the excitation line (12) can substantially exceed the homogeneous linewidth $2 \Gamma$. Its temperature dependence may also be essentially modified as compared to that of the homogeneous line. For a simple case $\left(N=2, \bar{n}_{1}=\bar{n}_{2}=1 / 2\right)$ the situation is depicted in 

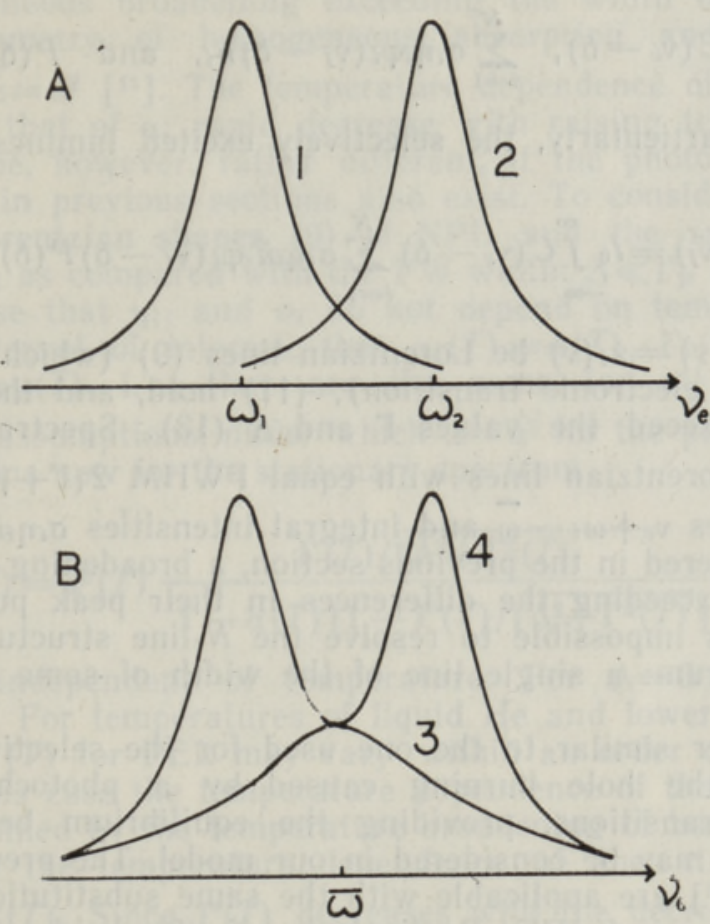

A - Absorption spectra of two configurations of an impurity $(1,2), \Delta=\left(\omega_{2}-\omega_{1}\right) / 2=$ $=2 \Gamma, \bar{n}_{1}=\bar{n}_{2}=0.5$;

$B$ - Resulting stationary excitation spectrum (3), compared with that in the absence of phototransitions between configurations (4).

Figure, where the spectra $x_{1}, x_{2}$, and the resulting stationary excitation spectrum are given. For a comparison, the excitation spectrum is given for the case where photoinduced transitions between configurations are absent, clearly exhibiting two distinct lines.

\section{Static inhomogeneity}

The static variations of local conditions in the matrix essentially affect impurity spectra. Simplifying in some respect the real situation, we suppose these variations to result only in spectral shifts equal for all configurations of a given impurity but different for different impurities:

$$
\boldsymbol{x}_{i}^{k}(v)=\chi_{i}\left(v-\delta_{k}\right), \quad \varphi_{i}^{k}(v)=\varphi_{i}\left(v-\delta_{k}\right),
$$

with the upper index $k$ labelling impurities. Particularly, in (9) one has to substitute $\omega_{i} \rightarrow \omega_{i}^{0}+\delta_{k}$. To describe such a system, an inhomogeneous distribution function (IDF) $P(\delta)$ has to be introduced.

In this case, all the results, obtained for the selective excitation of inhomogeneous spectra $\left[{ }^{3}\right]$, hold for our stationary case, the only difference being the replacement of the homogeneous absorption and luminescence spectra as well as IDF by 


$$
C\left(v_{e}-\delta\right), \quad \sum_{i=1}^{N} \sigma_{i} \eta_{i} \varphi_{i}\left(v_{f}-\delta\right) \bar{n}_{i}, \text { and } P(\delta),
$$

respectively. Particularly, the selectively excited luminescence spectrum is given by

$$
I_{f}^{\infty}\left(v_{f}\right)=I_{0} \int_{-\infty}^{\infty} C\left(v_{e}-\delta\right) \sum_{i=1}^{N} \sigma_{i} \eta_{i} \bar{n}_{i} \varphi_{i}\left(v_{f}-\delta\right) P(\delta) \mathrm{d} \delta .
$$

Let now $\varphi_{i}(v)=x_{i}(v)$ be Lorentzian lines (9) (which is the situation for the purely electronic transition), (11) hold, and the width of IDF substantially exceed the values $\Gamma$ and $\Delta$ (13). Spectrum (16) is then a sum of $N$ Lorentzian lines with equal FWHM $2\left(\Gamma+\sqrt{\Gamma^{2}+\Delta^{2}}\right)$ and of peak frequencies $v_{e}+\omega_{i}-\bar{\omega}$ and integral intensities $\sigma_{i} \eta_{i} \bar{n}_{i}$. Compared to the case considered in the previous section, a broadening of luminescence lines occurs, exceeding the differences in their peak positions $\omega_{i}-\omega_{j}$. Therefore, it is impossible to resolve the $N$-line structure in the luminescence spectrum: a single line of the width of some $\Delta$ is observable (at $\Delta>\Gamma)$.

In a manner similar to the one used for the selective excitation of luminescence, the hole burning caused by a photochemical reaction slower than transitions, providing the equilibrium between different configurations, may be considered in our model. The previous results on hole burning $\left.{ }^{6}{ }^{6}\right]$ are applicable with the same substitution of the homogeneous spectra and IDF. Particularly, if (9) holds, the unsaturated «slow» hole in the excitation spectrum burned in and recorded at quasiequilibrium for «fast» transitions is of a Lorentzian form with the halfwidth $4 \sqrt{\Delta^{2}+\Gamma^{2}}$, exceeding the value $4 \Gamma$. When the registration is carried out under non-equilibrium conditions, a hole may be observed, which is caused by the redistribution of impurities between different configurations during the burning stage. The width of such a hole is of the order of $\Delta$ as well (at $\Delta>\Gamma$ ), provided the equilibrium was reached in the burning stage. It should be mentioned that a similar hole broadening can also take place in the absence of transitions between different configurations (purely static inhomogeneity). This occurs when several close-lying lines at uncorrelated frequencies are present in the homogeneous spectrum $\left[{ }^{10}\right]$. However, in the latter case a narrow hole of a width equal to the double width of these homogeneous lines is also present. In our model such a narrow hole is absent.

\section{Temperature dependence of spectra}

Large differences in the NPL and PW widths in cooperation with the phototransformations and static inhomogeneous broadening considered in the previous sections, may result in an unusual temperature dependence of selectively excited luminescence spectra. In the case of a purely static inhomogeneous broadening (all impurities in a fixed configuration) comparable with or exceeding the width of PW, a characteristic picture of a narrow line and broad sideband is observable in the selectively excited luminescence spectrum. Although the observable sideband in the spectrum is not just the homogeneous PW [ $\left.{ }^{3}\right]$, an «experimental» DWF $\tilde{\alpha}$ may be introduced which is equal to the ratio of the line and 
total (line plus sideband) intensities in the spectrum measured. For large inhomogeneous broadening exceeding the width of PW, in case the mirror symmetry of homogeneous absorption and luminescence spectra holds, $\tilde{\alpha}=\alpha^{2}\left[{ }^{11}\right]$. The temperature dependence of $\tilde{\alpha}$ is qualitatively similar to that of $\alpha$ : rapid decrease with raising temperature. The situation may be, however, rather different, if the photoinduced transitions regarded in previous sections also exist. To consider this we still suppose the Lorentzian shapes (9) of NPL and the smallness of the dispersion of $\omega_{i}$ as compared with the PW width: $\Delta \ll \Gamma_{p}$ and (11) holds. We also suppose that $\eta_{i j}$ and $\sigma_{i}$ do not depend on temperature in the temperature interval of interest, that $\alpha_{i}(T)=\alpha(T), \Gamma_{i}(T)=\Gamma(T)$, and $\omega_{i}(T)-\omega_{i}(0)=v(T)$, i. e., they are the same for all configurations. With the same assumptions, under which $\tilde{\alpha}=\alpha^{2}$ for the purely static case holds, one obtains now for the stationary spectrum

$$
\tilde{\alpha}(T)=\alpha^{2}(T) \frac{\Gamma(T) / \sqrt{\Delta^{2}+\Gamma^{2}(T)}}{1-\alpha(T)\left[1-\Gamma(T) / \sqrt{\Delta^{2}+\Gamma^{2}(T)}\right]},
$$

with $\Delta$ being independent of temperature. For $\Delta=0$ (17) gives the previous result. For temperatures of liquid He and lower $\alpha(T) \approx \alpha(0)=$ $=$ const., but $\Gamma(T)$ for PEL may vary within an order of magnitude or more $\left[{ }^{9}\right]$. In this case the temperature dependence of the «experimental» DWF is determined by the temperature broadening of homogeneous PEL rather than by the temperature dependence of the «true» DWF. For $\Delta \gg \Gamma \tilde{\alpha}(T) \sim \Gamma(T)$. Since $\Gamma(T)$ decreases with the decrease of temperature, a behaviour anomalous for the «true» DWF may be observed for the «experimental» DFW at low temperatures. The physical reason for this is the circumstance that to the broad sideband in the experimental spectrum contribute also the impurities excited via PW $\left[{ }^{3}\right]$. The number of such impurities is not seriously affected by spectral shifts of the order of $\Delta$, which is supposed to be small compared with the width of $\mathrm{PW}$. At the same time the number of the impurities excited via NPL, contributing to the narrow line, may be substantially reduced by the redistribution of impurities between different configurations.

\section{Experimental problems}

To observe experimentally the effects discussed above, the following must be fulfilled: the intensity of luminescence at equilibrium must be sufficiently high for the given registration sensitivity (i), and the equilibrium must be reached at real times of the experiment (ii).

In our model with Lorentzian absorption lines (9) the integral intensity of luminescence lines depends on the ratio $\Delta / \Gamma$. Compared with the case $\Delta=0$, the intensity is reduced by a factor of $1+(\Delta / \Gamma)^{2}$ in the absence of static inhomogeneity (excitation at $v_{e}=\bar{\omega}$ ) and by $\sqrt{1+(\Delta / \Gamma)^{2}}$ in the presence of static inhomogeneous broadening, exceeding $\Delta$.

To reach equilibrium for actual values of excitation frequencies $\left(\left|v_{e}-\bar{\omega}\right| \leqslant \Delta\right)$ a characteristic time $\tau$ may be estimated by

$$
\tau^{-1}=\pi I_{0} \lambda_{e}^{2} \alpha \bar{\eta} \Gamma_{0} \Gamma / \Delta^{2} .
$$


Here $\lambda_{e}$ is the excitation wavelenght, $\bar{\eta}$ is a characteristic value of the yields $\eta_{i j}(i \neq j), 2 \Gamma_{0}$ is the radiational linewidth. (18) is obtained as an estimation of minimal value of kinetic coefficients in (1), using a wellknown formula for integral cross-section $\sigma=\pi \lambda_{e}^{2} \Gamma_{0}$. A substitution of characteristic values $\lambda_{e}=500 \mathrm{~nm}, I_{0}=10^{22} \mathrm{~m}^{-2} \mathrm{~s}^{-1}\left(0.5 \mathrm{~W} \cdot \mathrm{cm}^{-2}\right), 2 \Gamma_{0}=$ $=10^{-3} \mathrm{~cm}^{-1}, 2 \Gamma=10^{-2} \mathrm{~cm}^{-1}, \alpha=0.5, \Delta=10 \mathrm{~cm}^{-1}, \bar{\eta}=10^{-2}$ into (18) gives $\tau \approx 1$ s. This demonstrates that for the transitions between different configurations with the yields of the order of $10^{-2}$ at the excitation intensities moderate for $\mathrm{CW}$ lasers, the times for reaching equilibrium via purely electronic absorption are rather realistic for the values $\Delta$ up to $10 \mathrm{~cm}^{-1}$. There is some evidence about the observation of such small lineshifts for molecular impurities in organic glasses $\left[{ }^{12,13}\right]$, attributed to some rearrangement of the matrix rather than to the inner photochemistry of impurities. It seems appealing to apply our results to the latter systems to explain such experimental facts as large holewidths in glasses $[5,9,12,13$,$] , exceeding those for the same molecule at the same$ temperature in crystals by an order of magnitude or more and revealing unusual (for crystals) temperature dependence $\left[{ }^{9}\right]$ and an anomalous low-temperature behaviour of the observed DWF [ $\left.{ }^{13}\right]$.

\section{Acknowledgement}

The authors are indebted to K. Rebane, L. Rebane, and R. Avarmaa for useful discussion and valuable remarks.

\section{REFERENCES}

1. S z a b o, A., Phys. Rev. Lett., 25, № 14, 924-926 (1970).

2. Персонов Р. И., Альшиц Е. И., Быковская Л. А., Письма в ЖЭТФ, 15 , вып. 10, 609-612 (1972).

3. А в а р м а а Р., Изв. АН ЭССР, Физ. Матем., 23, № 3, 238-247 (1974).

4. Гороховски й А. А., Ка арли Р. К., Ребане Л. А., Письма в ЖЭТФ, 20, вып. 7, 474-479 (1974).

5. Kharlamov, B. M., P e r s o nov, R. I., B y kovskaya, L. A., Opt. Commun., 12, № 2, $191-193$ (1974).

6. Гороховский А. А., Кик ас Я. В., Ж. прикладной спектроскопии, 28, № 5 , $832-838$ (1978).

7. Агеева Л. Е., Пр жев уски й А. К., Толстой М. Н., Ша повалов В. Н., Физ. твердого тела, 16, вып. 6, 1659-1662 (1974).

8. Р ебане К. К., Элементарная теория колебательной структуры спектров примесных центров кристаллов, М., «Наука», 1968.

9. Гороховский А. А., Кикас Я. В., Пальм В. В., Ребане Л. А., Физ. твердого тела, 23, вып. 4, 1040-1047 (1981).

10. Никитин В. И., Соскин М. С., Хи жняк А. И., Қвант. электроника, 5, вып. 6, 1375-1379 (1978).

11. Персонов Р. И., Изв. АН СССР, Сер. физ., 42, вып. 2, $242-252$ (1978).

12. H a y e s, J. M., S m a 11, G. J., Chem. Phys., 27, № 1, 151-157 (1978).

13. H a y e s, J. M., S m a 1 1, G. J., Chem. Phys. Lett., 54, № 3, 435-438 (1978).

Academy of Sciences of the Estonian SSR, Institute of Physics 


\section{R. JAANISO, J. KIKAS}

\section{AUGU POLLETAMISE MÕJU SELEKTIIVSELT ERGASTATUD SPEKTRITELE}

On vaadeldud tahkes maatriksis asuvat lisandisüsteemi, kus lisandi spektraalselt mitteekvivalentsete kvaasistabiilsete konfiguratsioonide vahel on võimalikud optiliselt indutseeritud üleminekud. Juhul kui monokromaatse ergastuse tagajärjel on saabunud dünaamiline tasakaal erinevate konfiguratsioonide vahel, ei sõltu luminestsentsispekter (7) ergastuse sagedusest. Kui tasakaal saabub neeldumise tōttu üksikute konfiguratsioonide neeldumisjoontes, mis omavad Lorentzi kuju, siis sisaldab süsteemi ergastusspekter ühe Lorentzi joone, mille laius on määratud erinevate konfiguratsioonide optiliste üleminekute sageduste dispersiooniga. Uleminekud erinevate konfiguratsioonide vahel pōhjustavad mittehomogeensetesse spektritesse põletatud aukude laienemise ja selektiivselt ergastatud luminestsentsijoonte anomaalse temperatuurisõltuvuse. Viimaseid nähtusi on varem jälgitud klaasmaatriksites olevate lisandite puhul.

\section{Р. ЯАНИСО, Я. КИКАС}

\section{ВЛИЯНИЕ ВЫЖИГАНИЯ ПРОВАЛА НА СЕЛЕКТИВНО ВОЗБУЖДЕННЫЕ СПЕКТРЫ}

Рассматривается замороженная в твердотельной матрице примесная система, в которой между спектрально неэквивалентными квазистабильными конфигурациями примеси имеют'место оптически индуцированные переходы. При монохроматическом возбуждении в случае достижения равновесия между конфигурациями спектр люминесценции (7) перестает зависеть от частоты возбуждения. Если равновесие достигается за счет поглощения в лоренцевых линиях отдельных конфигураций, то спектр возбуждения системы содержит одну лоренцеву линию с шириной, определяемой дисперсией частот оптического перехода разных конфигураций. При селективном возбуждении в случае дополнительного статического неоднородного уширения переходы между конфигурациями обусловливают уширение выжигаемых в спектре провалов и аномальную температурную зависимость интенсивности линий люминесценции в области низких температур. Подобные явления ранее наблюдались для примесных систем в стеклообразных матрицах. 